\title{
Fix that genome?
}

\author{
William M. Adams and Kent H. Redford
}

Shortly after Valentine's Day 2021, photographs of a cute baby black footed ferret Mustela nigripes graced newsfeeds (Imbler, 2021). The unusual thing about the ferret was its parentage-it was a clone of a female, Willa, who died in captivity in the 1980 os without breeding, and whose cells had been cryopreserved. Cells from Willa have now been used to create an embryo by interspecies somatic cell nuclear transfer, which was inserted into the womb of a domestic ferret surrogate mother and successfully brought to term (Wisely et al., 2015). Cue the cute photo-op for a photogenic ferret kit, named Elizabeth Ann.

Press articles about the event hailed the 'genetic rescue' or 'genetic restoration' of previously lost elements of the black ferret genome. This approach for enhancing the restricted genomes of threatened species seems to be working its way into the conservation mainstream (Sandler et al., 2021). The ferret cloning was done by a consortium that included the U.S. Fish \& Wildlife Service, ViaGen (a Texas-based pet and horse cloning company), Revive \& Restore, the Association of Zoos and Aquariums, and San Diego Zoo (Revive \& Restore, 2021).

How should conservationists think about this? On the one hand it seems amazingly cool and clever. Here you have a species thought extinct in the 1970s until rediscovered in the wild in 1981 and captive bred since 1986. Wild releases of black-footed ferrets began in Montana in 1994, but population recovery has been slow, limited by disease and low reproductive success as a result of inbreeding depression (Dobson \& Lyles, 2000). All living black-footed ferrets are descended from only seven individuals, and thus contain only a portion of the original genetic variation of the species (Wisely et al., 2015). The cloning project recovered genetic material not currently represented in the living black-footed ferret population, and inserted it into a captive animal (Elizabeth Ann), with the plan that Willa's genes could be spread through the captive and wild populations.

This neat piece of genetic legerdemain is an example of a much wider range of interventions being made into the genomes of wild animals and plants that is increasing in scope and complexity. Increasingly, these focus not on cloning but on gene editing and the harnessing of the techniques of

William M. AdAms The Graduate Institute Geneva, Rue de Lausanne 132, 1202 Geneva, Switzerland, and Department of Geography, University of Cambridge, Downing Place, Cambridge, UK. E-mail wa12@cam.ac.uk

Kent H. Redford Archipelago Consulting, Portland, Maine, USA, and Department of Environmental Studies, University of New England, Biddeford, USA synthetic biology for conservation purposes. This has been growing over the last 10 years, with a broadening pool of writing about what might be done (Redford et al., 2014; Piaggio et al., 2016; Phelps et al., 2019; Redford et al., 2019; Redford \& Adams, 2021).

Applications being discussed include engineering of the genomes of invasive species or disease vectors (to stop them breeding), and of the genomes of threatened species to enhance their probability of survival. Ideas being explored include engineering corals, to enhance their survival in warming and acidifying oceans, and wild species threatened by disease, to increase their resistance.

One approach to the novel technologies of gene editing, as with cloning, is to embrace them as a much-needed new conservation tool: an innovative, efficient and potentially rapid fix for otherwise difficult or intractable conservation problems. However, genetic enhancement or correction for conservation purposes may not be straightforward. Most obviously, there are critically important questions about the costs and benefits of genetic engineering wild species, about the risks of ecological impacts and unplanned gene flow from engineered organisms, and about procedures for approving the release of engineered wild species and engineered gene drives (Sandler, 2019; Redford \& Adams, 2021; Sandler et al., 2021).

But beneath these important issues lies a deeper question about the implications of these technologies for our understanding of nature and what is natural. What does it mean to edit the genes of a wild species to enhance or correct its genome to promote its conservation?

The idea that conservation is about protecting what is natural is deeply coded into conservation thinking. Generations of conservationists have stood for the principle that nature-the nature that matters-is something that has come by itself, something separate from and threatened by human action. Of course, ecologists have accepted since Tansley that many ecosystems are shaped by human actions, and-arguably-in this era of anthropogenic climate change, all ecosystems are now human-influenced. But as Bill McKibben (1990, p. 54) pointed out, even as nature is damaged by human actions, 'our faith in its essential strength remains'.

So what does it mean to be able to manipulate the genomes of wild species? Arguably, it threatens to undermine the concept of nature itself, if one means by this something beyond the human. It starts to do what domestication does, adapting and shaping species to fit human understandings and purposes. Even if, as with black-footed ferrets, that 
purpose is to ensure the survival of particular forms of life, it takes the shaping of that life into human hands.

Does this matter? Is the use of genetic technologies to shape the genomes of rare or nuisance species any different from the use of a chainsaw, herbicide, rat poison or fire to shape ecosystems or determine the size of animal or plant populations? They are also technologies, but longestablished, familiar ones. Gene editing technologies are unfamiliar. They may not, in theory, be any more unnatural than other technologies regularly used in conservation, but they are by any standards novel. They are tools without a conservation history. Their impacts are not easy to predict, and experience with their deployment is minimal (Redford \& Adams, 2021).

So, for example, one might compare the use of CRISPR to edit the genome of the skin microbiome of a threatened amphibian, to increase resistance to disease, with a chainsaw used to control invasive trees. Both CRISPR and the chainsaw are technologies. Both have important biological and ecological impacts when applied by their human handler. Yet they are very different in their effects, and how easily those effects can be observed.

The chainsaw can only cut one tree at a time, it takes a while to do so, and the results are immediately obvious to any observer. If someone thinks the cutting is unwise, or illegal, there is the potential they can influence the management decision. Gene editing (using CRISPR-Cas9 or an equivalent engineered genetic device) allows a genome to be reshaped in a laboratory, and the process can only be observed by other scientists. Moreover, the effects of the changes are not necessarily confined to one individual but can persist down the generations, as human-caused genomic changes undergo natural selection when the altered organism joins its ecological community. It is not surprising if the two technologies of chainsaw and CRISPR trigger different concerns about risk, and the willingness of society to accept technologies with unknown effects.

Genetic technologies may prove a wonderful tool for conservation if their use comes to be accepted by the public and if a way to regulate them is resolved (Novak et al., 2018; Sandler et al., 2021). But without doubt they come with a lot of baggage. They share the burden of public unease about genetic engineering in general. But more immediately for conservation, they challenge many of the ideas on which scientists and managers depend in making their case for the importance of nature: that it stands apart from the human-fashioned world.

There is a great deal of thinking and discussion required before the techniques of genetic enhancement and suppression could be thought of as routine in conservation.
As we discuss in our book Strange Natures (Redford \& Adams, 2021), it is urgent that conservationists think hard about the powers synthetic biology offers, rather than accepting simplistic arguments about new tools in a time of crisis or that all genetic engineering is wrong. Good decisions will demand careful navigation of immensely complex practical and ethical terrain (Redford \& Adams, 2021; Sandler et al., 2021).

Meanwhile, Elizabeth Ann appears alive and well in a Montana breeding facility. Her genome contains genetic information once lost, but now re-inserted into the black footed ferret lineage by its human managers. From this novel genetic reboot, natural and human selection are intertwining to fashion the future of the species.

\section{References}

Dobson, A. \& Lyles, A. (200o) Black-footed ferret recovery. Science, $88,985-988$

ImbleR, S. (2021) Meet Elizabeth Ann, the first cloned black-footed ferret. New York Times, 18 February 2021. nytimes.com/2021/02/18/ science/black-footed-ferret-clone.html [accessed 17 April 2021].

McKibben, B. (1990) The End of Nature. Penguin Books, Harmondsworth, UK.

Novak, B.J., Maloney, T. \& Phelan, R. (2018) Advancing a new toolkit for conservation: from science to policy. The CRISPR Journal, 1, 11-15.

Phelps, M.P., Seeb, L.W. \& Seeb, J.E. (2019) Transforming ecology and conservation biology through genome editing. Conservation Biology, 34, 54-65.

Piaggio, A.J., Segelbacher, G., Seddon, P.J., Alphey, L., Bennett, E.L., CARLSON, R.H. et al. (2016) Is it time for synthetic biodiversity conservation? Trends in Ecology \& Evolution, 32, 97-107.

Redford, K.H. \& AdAms, W.M. (2021) Strange Natures: Conservation in the Era of Genome Editing. Yale University Press, New Haven, USA.

Redford, K.H., Adams, W.M., Carlson, R., Mace, G. \& Cecarelli, B. (2014) Synthetic biology and the conservation of biodiversity. Oryx, 48, 330-336.

Redford, K.H., Brooks, T.M., Macfarlane, N.B.W. \& Adams, J.S. (eds) (2019) Genetic Frontiers for Conservation: An Assessment of Synthetic Biology and Biodiversity Conservation. Technical assessment, IUCN, Gland, Switzerland.

Revive \& Restore (2021) The Black-Footed Ferret Project. reviverestore.org/projects/black-footed-ferret [accessed 20 April 2021].

SANDLER, R.L. (2019) The ethics of genetic engineering and gene drives in conservation. Conservation Biology, 34, 378-385.

SAndLer, R.L., Mose, L. \& Wisely, S.M. (2021) An ethical analysis of cloning for genetic rescue: case study of the black-footed ferret. Biological Conservation, 257, 109118.

Wisely, S.M., Ryder, O.A., SAntymire, R.M., Engelhardt, J.F. \& NovaK, B.J. (2015) A road map for 21st century genetic restoration: gene pool enrichment of the black-footed ferret. Journal of Heredity, 581-592. 